\title{
THE PROCESS OF NURSING A CHILD WITH HADDAD SYNDROME
}

\author{
Aneta Kołodziejska ${ }^{1 C, D}$, Dominika Kołodzeike ${ }^{2 C, D}$, Anna Małecka-Dubiela ${ }^{1 C, D}$
}

\author{
IInstitute of Nursing, Department of Pediatric and Internal Medicine Nursing, Medical University \\ of Gdańsk, Poland \\ ${ }^{2}$ Institute of Nursing, Student Research Group of the Pediatric and Internal Medicine Nursing \\ Institute, Medical University of Gdańsk, Poland
}

Authors' contribution:

A. Study design/planning • B. Data collection/entry $\bullet$ C. Data analysis/statistics $\bullet$ D. Data interpretation $\bullet$ E. Preparation of manuscript $\bullet$ F. Literature analysis/search $\bullet$ G. Funds collection

\author{
Address for correspondence: \\ Aneta Kołodziejska \\ Institute of Nursing \\ Department of Pediatric \\ and Internal Medicine Nursing \\ Medical University of Gdańsk \\ 7/15 Dębinki St., 80-952 Gdańsk, Poland \\ e-mail: aneta.kolodziejska@gumed.edu.pl \\ SUBMITTED: 02.08 .2020 \\ ACCEPTED: 15.10 .2020 \\ DOl: https://doi.org/10.5114/ppiel.2020.103538
}

\begin{abstract}
Haddad syndrome is a combination of congenital central hypoventilation and Hirschsprung's disease. This disease is very rare and causes mainly sleep apnoea and problems with intestinal peristalsis. Haddad syndrome is characterised by hereditary disorders of the autonomic nervous system and the lack of nerve ganglia in the distal part of the large intestine.

The purpose of the above work is to illustrate the role of the nurse in caring for a child with Haddad syndrome and to present diagnoses and interventions based on the ICNP terminology, which the staff should include in the treatment process.

In this work the method of literature analysis as well as the individual case was used. It was also based on interview, observation, and interpretation of the patient's medical records. The study was conducted in September 2018 during a home visit as part of nursing care for a mechanically ventilated patient.

The patient was diagnosed. Eight nursing diagnoses were formulated. These included: apnoea, impaired airway patency, abdominal pain, weakness, underweight, disturbed sleep, lack of appetite, and fatigue. The International Classification of Nursing Practice ICNP ${ }^{\oplus}$ is a huge source of terms that facilitate, speedup, and make the nurse's work more effective. It enables the documenting and describing of specific diagnoses, interventions, and results selected and applied to them [6]. The use of an appropriate diet and pharmacotherapy proved to be effective, which improved the patient's condition and allowed her to return to normal functioning.
\end{abstract}

Key words: ICNP ${ }^{\circledast}$, Haddad syndrome, Hirschsprung's disease, Ondine's curse, nursing process.

\section{INTRODUCTION}

Haddad syndrome is a very rare disease in which congenital central hypoventilation syndrome (CCHS), or Ondine's syndrome, occurs together with Hirschsprung's disease. The first one is characterised by a disorder of the autonomic nervous system that affects breathing. It causes hypoventilation (especially during sleep), resulting in a shortage of oxygen and a build-up of carbon dioxide in the blood. This change does not only affect the process of breathing but causes neurological disorders [1]. It is a terminal, incurable disease caused by a homeotic gene mutation $P H O X 2 B$. The $P H O X 2 B$ gene is known for encoding; it codes for a homeodomain transcription factor. It is expressed exclusively in the nervous system in most neurons that control the viscera. Typically, the disease is diagnosed soon after the baby is born. Most of the patients must be on mechanical ventilation during their sleep for the rest of their life. The patients in more severe condition require mechanical ventilation also during the day [1-5]. Hirschsprung disease most often occurs together with hypoventilation syndrome. It is an intestinal disorder characterised by the lack of nerve ganglia in the distal part of the large intestine, which is the reason for intestinal failure and leads to bowel obstruction and many uncomfortable symptoms which the patient experiences (megacolon or segmental dilation followed by the obstruction of the further part of the large bowel is caused by the lack of enteric nervous system). The combination of these 2 diseases is called Haddad syndrome [3]. In 2004 it was estimated that there are 300 patients worldwide diagnosed with congenital central hypoventilation syndrome. Thanks to the development of medicine and diagnostics, they are more often detected and treated.

The disease is called the Ondine's curse. According to mythology, the nymph Ondine fell in love with a man who was unfaithful to her. She cursed him to remain awake in order to control his own breathing [2]. 


\section{MATERIAL AND METHODS}

A literature review as well as a case study method were used in this work. An interview, observation, the analysis of medical records and measurements of basic vital signs were performed. The study was conducted during a home visit of a child receiving longterm mechanical ventilation. Written consent was provided by the parent of the child. The parent was informed that the data would be anonymous.

\section{CASE STUDY}

The study was conducted during a home visit of an 8-year-old child receiving long-term mechanical ventilation. The aim was to assess the health condition of the patient.

The child was born in 2010. The parents were healthy, and it was the first pregnancy. The birth was natural. The child received an overall Apgar score of 10 . After 10 minutes the skin turned to blue, and shortness of breath and hypotonia occurred. The child required oxygen therapy and was intubated. A tracheotomy was performed in the second month of the child's life due to a chronic respiratory failure. A differential diagnosis was performed, during which the following were excluded: neuromuscular diseases, congenital or nosocomial infections, lung diseases, and metabolic or heart disorders. Parenteral nutrition was provided until the $27^{\text {th }}$ day of the child's life. Intestinal obstruction and a general infection occurred during the $9^{\text {th }}$ week of life. The ileostomy was done, and the samples were collected for histopathological examination, which revealed the absence of nerves in the large intestine. The child was diagnosed with Haddad syndrome due to many factors, including respiratory failure that increases during sleep, as well as Hirschsprung's disease. The girl had a Broviac catheter inserted and started parenteral nutrition therapy as well as home mechanical ventilation. The patient had a surgery to remove the affected section of bowel. The next step was to restore the continuity of the gastrointestinal tract. Currently the child is breathing independently when awake. During sleep the girl has to be connected to a ventilator. Copious stools (8-10 a day) were a major issue in terms of taking care of the child's anus. The girl's proper body weight gain has been observed. The psychomotor development of the patient is delayed. Thanks to the early rehabilitation she started walking independently at the age of 20 months. During the visit, the condition of the child was good with no pathological changes of the skin. The temperature was $36.7^{\circ} \mathrm{C}$, pulse $104 \mathrm{bpm}$ (beats per minute), blood pressure 115/55 mmHg, $\mathrm{SpO}_{2}$ 93-98\%, and a small amount of residual mucus. The abdomen was soft, and no oedema occured. Additional issues were observed: temporary desaturation and loose stools. Periodic saturation measurement, tracheos- tomy care, and a high-protein and high-fat diet to prevent diarrhoea and flatulence were recommended. What is more, the parents were instructed to take care of the skin after bowel movement, apply ointment in case of chafing, and use PACV ventilation during sleep, when an infection occurs, or while travelling by car.

\section{THE PROCESS OF CHILD'S CARE USING THE INTERNATIONAL CLASSIFICATION FOR NURSING PRACTICE ICNP ${ }^{\circledR}$}

The International Classification for Nursing Practice provides the nursing language set and unification so that it is understood and globally used. Uniform and structured language (terminology) leads to an increase in the quality of care.

The International Classification for Nursing Practice is a new tool, which is a base for the nursing staff. It is rich in diagnoses and nursing interventions, which are the foundations of the care process and holistic care [6].

Psychosocial state of the child was assessed with the usage of selected Canadian Health Outcomes for Better Information and Care (C-HOBIC) scales and the indication of the nursing diagnoses ICNP ${ }^{\circledR}$.

$\mathrm{C}-\mathrm{HOBIC}$ system is the next tool with the aim of standardisation in nursing care. Thanks to its simple form it facilitates and reduces work focused on medical records. It results in having more time for the patient.

The scales used in assessing patient's condition in the C-HOBIC system are as follows:

- functional scale: Urinary Incontinence Scale, Activities of Daily Living (ADL);

- symptoms rating scale: fatigue, pain, dyspnoea [7].

\section{Diagnosis 1}

ICNP ${ }^{\circledR}$ : Apnoea [10035020].

Nursing interventions:

- monitoring respiratory status [10012196],

- monitoring cardiac status [10034285],

- monitoring blood oxygen saturation using pulse oximeter [10032047],

- assessing respiratory status using a monitoring device [10002799],

- oxygen therapy [10039369],

- assistive device therapy [10039158],

- collaborating with a physician [10023565],

- reporting the patient's status to a family member [10016825].

Outcomes: Effective gas exchange [10027993].

\section{Diagnosis 2}

ICNP ${ }^{\circledR}$ : Impaired airway clearance [10001051].

Nursing interventions:

- monitoring respiratory status [10012196], 
- encouraging breathing or coughing technique [10006834],

- teaching about exercise [10040125] + expectoration [10007362],

- chest therapy [10004221],

- respiratory tract suction [10044890] + tracheotomy [10019951],

- respiratory support maintenance with mechanical ventilation [10046258] + ventilator [10044842].

Outcomes: Effective airway clearance [10027964].

\section{Diagnosis 3}

ICNP $^{\circledR}$ : Abdominal pain [10043953]

Nursing interventions:

- consulting for pain management [10024331],

- nurse controlled analgesia [10039798],

- administering pain medication [10023084],

- monitoring pain [10038929],

- teaching about pain [10039115],

- administering nutritional supplement [10037037],

- massage therapy [10039189],

- monitoring bowel motility [10037211].

Outcomes: Reduced pain [10027917].

\section{Diagnosis 4}

ICNP ${ }^{\oplus}$ : Weakness [10022880].

Nursing interventions:

- evaluating response to fluid therapy [10007176],

- consulting home care service [10021816],

- reinforcing adherence [10024562],

- monitoring physiological status [10012183],

- administering medication [10025444].

Outcomes: Effective response to the therapy [10036423].

\section{Diagnosis 5}

ICNP ${ }^{\oplus}$ : Underweight [10027316].

Nursing interventions:

- teaching about diet [10046533],

- assessing dietary need [10037875],

- monitoring weight [10032121],

- teaching family about dietary regime [10026525],

- advancing dietary regime [10036447],

- assessing adherence to diet [10044481]. Outcomes: Effective weight [10027385].

\section{Diagnosis 6}

ICNP $^{\circledR}$ : Impaired sleep [10027226].

Nursing interventions:

- assessing sleep [10036764],

- teaching about sleep [10040380],

- providing bedtime routine [10039025],

- demonstrating relaxation technique [10024365],

- administering medication [10025444]. Outcomes: Adequate sleep [10024930].

\section{Diagnosis 7}

ICNP ${ }^{\circledR}$ : Lack of appetite [10033399].

Nursing interventions:

- assessing appetite [10038901],

- providing food [10041161],

- providing emotional support [10027051],

- administering medication [10025444],

- identifying attitude toward care [10009649],

- diversional therapy [10039348]. Outcomes: Positive appetite [10040333].

\section{Diagnosis 8}

ICNP ${ }^{\oplus}$ : Fatigue [10000695].

Nursing interventions:

- assessing fatigue [10026086],

- encouraging rest [10041415],

- assessing capabilities [10026040],

- managing fatigue [10046289],

- assisting with hygiene [10030821]. Outcomes: No fatigue [10034727].

\section{SUMMARY}

In the case of a child with Haddad syndrome, the care issues are highly diversified. The role of a nurse is very complex in terms of taking care of the patient and educating the parents. Establishing an order of actions and having a patient that follows the routine results in effective therapy without complications. Tracheostomy tube cleaning and dietary guidelines should be included in the terms of education. Moreover, psychological support should be provided. During home care, pain and symptoms associated with Hirschsprung's disease were the main ailments of a child with Haddad syndrome. The implementation of a proper diet and pharmacotherapy appeared to be effective, and so the condition of the patient improved. Thanks to regular nursing visits and building a therapeutic relationship, the child understands the reason for the treatment process and the symptoms that occur because of the disease. The patient was diagnosed. Eight nursing diagnoses were formulated. These included the following: apnoea, impaired airway patency, abdominal pain, weakness, underweight, disturbed sleep, lack of appetite, and fatigue.

\section{Disclosure}

The authors declare no conflict of interest.

\section{References}

1. Zaidi S, Gandhi J, Vatsia S, et al. Congenital central hypoventilation syndrome: An overview of etiopathogenesis, associated pathologies, clinical presentation and management. Auton Neurosci 2017; 11: 8-16.

2. Nannapaneni R, Behari S, Todd N, Mendelow A. Retracing Ondine's curse. Neurosurgery 2005; 57: 354-363. 
3. O’Brien L, Holbrook C, Vanderlaan M, et al. Autonomic function in children with congenital central hypoventilation syndrome and their families. Chest 2005; 18: 2478-2484.

4. Weese-Mayer D, Berry-Kravis E. Genetics of congenital central hypoventilation syndrome: lessons from a seemingly orphan disease. Am J Respir Crit Care Med 2004; 170: 16-21.

5. Tsoutsinos A, Karanasios E, Chatzis A. Haddad syndrome. Hellenic J Cardiol 2016; 57: 45-47.

6. Kilanska D, Grabowska H. ICNP® - Basic solutions, strategy, nursing practice (knowledge management), education and the place in the IT system of the health care. In: Kilanska D (Ed.), The International Classification for Nursing Practice. ICNP ${ }^{\circledast}$ in nursing practice. Medical Publishing House PZWL, Warsaw 2014; 50-55.

7. Nursing care results quality indicators according to C-HOBIC. 2015. http://a.umed.pl/pl/_akt/inf_tmp/2015/wskazniki\%20 jakosci\%2OHOBIC\%20-\%20skale\%20ICNP.pdf. Accessed: 1.02.2019. 